\title{
Pre-Existing Distortions, Inter-Industry Rent Seeking, and the Welfare Cost of Policies Subject to Influence
}

\author{
by Alex Robson*
}

Accepted for publication at Economic Papers

\begin{abstract}
It is well known that when there are existing distortions in related markets, partial equilibrium estimates of the welfare costs of new distortions using the standard "Harberger triangle" may be misleading [Goulder and Williams (2003)]. We show that similar general equilibrium considerations also play an important role in the development of accurate estimates of the costs of rent seeking. Producers in other markets will have an incentive to engage in additional rentseeking activity to suppress or encourage the establishment of new distortions in hitherto undistorted markets. In these situations, the total amount of resources spent on trying to encourage or discourage a new distortion or increasing an existing distortion can exceed the sum of the partial equilibrium Harberger (1964) “triangle” and Tullock (1967) “rectangle”. The analysis and results contrast sharply with standard general equilibrium measures of the welfare costs of distortions and the general theory of second best, which hold that introducing a new distortion or increasing an existing distortion may, in some instances, be welfare-improving.
\end{abstract}

Keywords: Rent Seeking, Lobbying.

JEL Classification Codes: H29, H30.

\footnotetext{
* Department of Accounting, Finance and Economics, Griffith Business School, Nathan Campus, Nathan, Qld, 4111. email: a.robson@griffith.edu.au. Ph +61 737357644.
} 


\section{Introduction}

What are the factors that determine the extent to which economic rents are dissipated? A range of explanations have been examined in the literature, including returns to scale and the functional form of the contest success function, the number of players and barriers to entry, and preferences towards risk, the asymmetry among the players, the source of the rent, the nature of the rent and the nature of the rent setter. ${ }^{1}$ This paper shows that by ignoring the rent-seeking incentives of producers in other markets, the standard Tullock rectangle will tend to underestimate the overall costs of rent-seeking.

Consider the following example. Suppose that bread producers lobby the government to introduce a distortion into the bread market, driving a wedge between consumer marginal value (i.e. price) and marginal cost and creating economic rents. Tullock (1967) argues persuasively that in this setting, at least part of the rent (and, under some conditions, all of it) should be considered social waste. Bread producers will use resources to try to capture these rents, and consumers will also use resources to oppose the distortion. The devotion of these resources does not generate any additional production or income, and instead merely redistributes income, and so is socially wasteful.

Suppose that the size of this Tullock rectangle is $\$ 10$ million. Further, assume that there is a preexisting distortion in the butter market which, when it was introduced, had the effect of increasing the price of butter, reducing the quantity demanded for butter, but providing rents to butter producers of \$5 million. Finally, assume that bread and butter are complements.

\footnotetext{
${ }^{1}$ For a recent survey of the rent seeking literature, see Hillman (2013). Congleton, Hillman and Konrad (2008) also provide an overview of rent seeking. Chapter 15 of Mueller (2003) and Nitzan (1994) provide earlier surveys. Konrad (2009) provides a book length treatment of contests that include cases where the contest may be designed to be socially beneficial, as well as rent seeking contents which are not socially beneficial. Bhagwati and Srinivasan (1980), Bhagwati (1982) and Varian (1989) consider rent seeking in multi-market settings. Finally, there are some natural links between our analysis and the important literature on lobbying and campaign contributions [see for example, the comprehensive survey of Grossman and Helpman (2001) and the references therein].
} 
Under these assumptions, the introduction of the new distortion in the bread market will reduce the demand for butter, and reduce some of the rents enjoyed by butter producers.

Suppose that as a result, butter producers stand to lose $\$ 3$ million of their original $\$ 5$ million in rents. Butter producers will have an incentive to lobby against the policy sought by bread producers. This phenomenon is summarized perfectly by Stigler's (1971) observation that:

"A third general set of powers of the state which will be sought by the industry are those which affect substitutes and complements. Crudely put, the butter producers wish to suppress margarine and encourage the production of bread." 2

Suppose that bread producers are willing to spend $\$ 9$ million to secure the policy and that butter producers are willing to spend $\$ 2$ million to stop it. The key point is that the value of resources spent encouraging and trying to prevent the policy change is \$11 million, which is larger than the increase the Tullock rectangle of $\$ 10$ million that would be received as rents by bread producers. In other words, if general equilibrium considerations are ignored, and the possibility that firms in other markets will lobby for or against the policy change is not taken into account, then the partial equilibrium "Tullock rectangle" underestimates the total value of resources devoted to rent seeking. Such general equilibrium considerations are rarely taken into account in the analysis of the costs of distortions. ${ }^{3}$

\section{General Equilibrium Estimates of the Welfare Costs of Distortions: The Standard Approach}

\footnotetext{
${ }^{2}$ See Stigler, G. (1971) page 6.

${ }^{3}$ As noted by an anonymous referee, an important exception in the Australian case is Sieper's (1982) classic examination of a range of Australian policy interventions. For example, in the context of protection against imports, Sieper notes (at page 12) that "Close inter-relationships between commodities on either the side of demand or of supply will on occasion give certain industries a keen interest in the tariff protection achieved by others.”
} 
To illustrate these ideas more generally, consider the following example, in which marginal costs are constant and distortions are positive. ${ }^{4}$ Figure 1 below illustrates an economy which is assumed to have constant marginal costs of production and $n \geq 2$ markets. We consider a subset of the economy consisting of two of these markets, A and B, and assume that marginal costs are constant and equal to $p_{A}^{0}$ and $p_{B}^{0}$ respectively in each of these markets. The initial competitive equilibrium allocation is the point $\left(x_{A}^{0}, x_{B}^{0}\right)$.

Suppose the government is considering intervening in market $\mathrm{B}$, which will lead to a distortion of prices and will create rents in that market. Market $\mathrm{A}$ is already subject to a similar price distortion of $\delta_{A}$. All other markets are assumed to be competitive and are not subject to regulation or intervention of any kind. In this example, we will assume that A and B are substitutes.

The initial distortion in A has caused a reduction in consumption in market $\mathrm{A}$ (from $x_{A}^{0}$ to $x_{A}^{1}$ ), and, since the goods are assumed to be substitutes, causes consumers to demand more of good B at every price (their ordinary demand curve shifts from $D_{B}$ to $D_{B}^{\prime}$ and they increase their consumption of good B from $x_{B}^{0}$ to $x_{B}^{1}$ ). As a result of the introduction of the distortion $\delta_{A}$ in market $\mathrm{A}$, the consumer ends up at the point marked 1 in each market. The distortion in A had its own welfare costs and rent seeking costs which were considered by Tullock (1967); we focus on the effect of introducing an additional distortion in a separate but related market.

\section{Figure 1}

\footnotetext{
${ }^{4}$ As pointed out by an anonymous referee and as discussed further below, the possible implications are in no way limited to the results of this special case.
} 


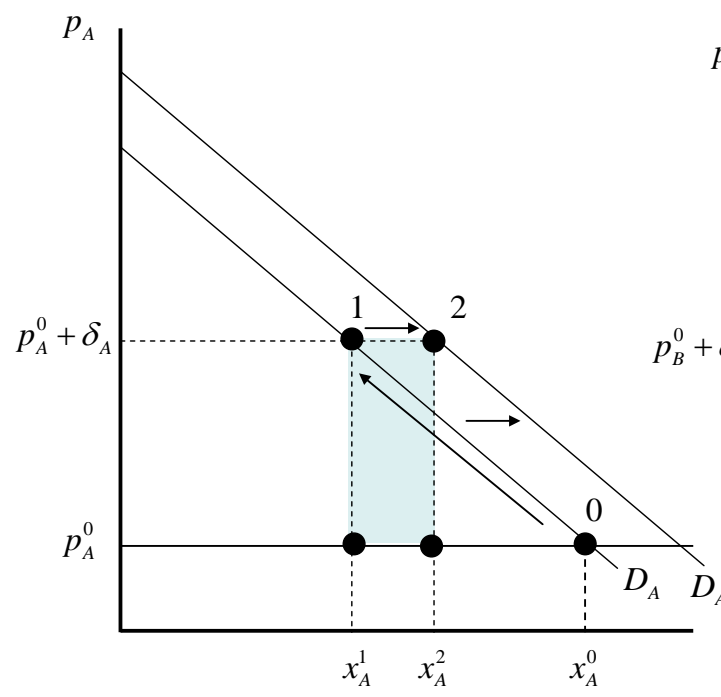

Market A

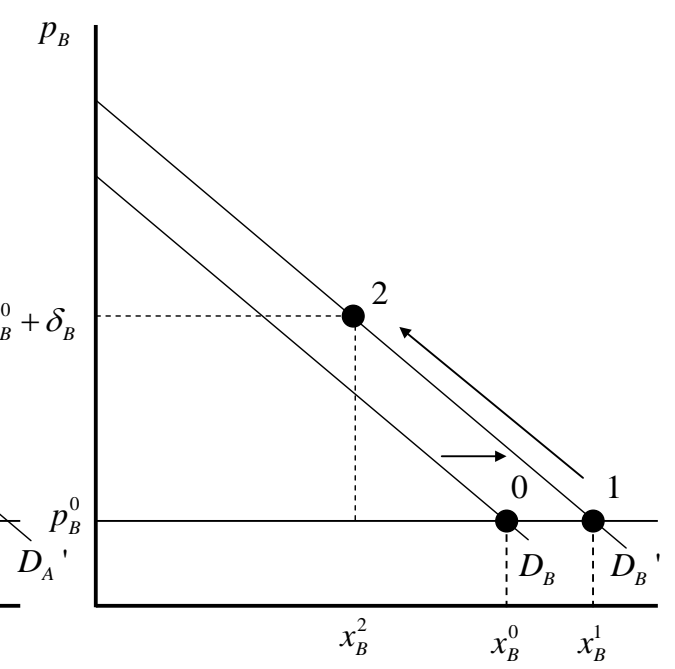

Market B

To this end, consider the introduction of a distortion of $\delta_{B}$ in market B. This distortion in B causes a reduction in consumption in market $B$ (from $x_{B}^{1}$ to $x_{B}^{2}$ ), and, since the goods are assumed to be substitutes, leads consumers to demand more of good A at every price - they increase their consumption of good A from $x_{A}^{1}$ to $x_{A}^{2}$. As a result of the introduction of $\delta_{B}$, the consumer ends up at the point marked “2” in each market.

Now consider the traditional Harberger general equilibrium measure of the welfare change that $\delta_{B}$ creates, which we denote by $\Delta W_{B}$. This measure is given by:

$$
\begin{aligned}
& \Delta W_{B}=\frac{1}{2} \delta_{B}\left(x_{B}^{2}-x_{B}^{1}\right)+\delta_{A}\left(x_{A}^{2}-x_{A}^{1}\right) \\
& \approx \frac{1}{2}\left(\delta_{B}\right)^{2} S_{B B}+\delta_{A} \delta_{B} S_{B A}
\end{aligned},
$$


where $s_{B B}=\frac{\partial x_{B}}{\partial p_{B}}<0$ is the slope of the inverse demand curve for good $\mathrm{B}, s_{A B}=\frac{\partial x_{A}}{\partial p_{B}}>0$ is the shift in demand for $\mathrm{A}$ in response to the price change in $\mathrm{B}$, and where we have used the fact that $\Delta x_{B} \approx \frac{\partial x_{B}}{\partial p_{B}} \Delta p_{B}=s_{B B} \delta_{B}$ and $\Delta x_{A} \approx \frac{\partial x_{A}}{\partial p_{B}} \Delta p_{B}=s_{A B} \delta_{B} \cdot 5$

The sign and size of the overall welfare change in (1) depends on two quantities: $\frac{1}{2} \delta_{B}\left(x_{B}^{2}-x_{B}^{1}\right)$, which is the triangle loss in market $\mathrm{B}$, and $\delta_{A}\left(x_{A}^{2}-x_{A}^{1}\right)$, which is the shaded rectangle in market A. ${ }^{6}$ Intuitively, the shaded rectangle in market $A$ adds to welfare because marginal value exceeds marginal cost in that market for the additional units that are consumed as a result of the introduction of the distortion in market B. Thus, in standard welfare economics the expression above can positive (i.e. a welfare gain relative to the initial distorted situation) if the second term exceeds the first in absolute terms. ${ }^{7}$

In other words, according to the theory of second-best, imposing the distortion in market B partially "unravels" the existing distortion in market A, and may even be welfare enhancing, relative to the initial distorted equilibrium. In the case in which $\mathrm{A}$ and $\mathrm{B}$ are substitutes, equation (1) indicates that this will be the case if the shaded area in market A exceeds the size of the triangle in market B. Indeed, when there are only two goods in the economy, a tax of equal proportions in each market is equivalent to a lump sum tax on the consumer's income and is regarded as non-distortionary for precisely this reason. As an aside, we note that by the first welfare theorem such combinations of taxes can never Pareto improve on the initial, undistorted competitive equilibrium at the point $\left(x_{A}^{0}, x_{B}^{0}\right)$.

\footnotetext{
${ }^{5}$ The approximation in (1) is exact if the demand curves are linear.

${ }^{6}$ Unless otherwise indicated, we use the convention that there is a welfare loss if $\Delta W<0$, and a welfare gain if $\Delta W>0$.

${ }^{7}$ Harberger (1971) derives a general expression for this welfare change when there are existing distortions in many other markets.
} 
To summarise the standard approach: when computing the welfare costs of changing an existing distortion or introducing a new one, it is not good enough to simply examine the triangle in the market in which the policy change is taking place. ${ }^{8}$ As we show in the next two sections, this also has implications for estimation of the costs of rent seeking behaviour.

\section{Incorporating the Costs of Rent Seeking Into the Standard Approach}

In the standard partial equilibrium welfare analytic approach, rents created by the introduction of a new distortion are treated as a pure transfer from consumers to producers. In other words, in the standard analysis, rent seekers are assumed to sit idly by as the new distortion sets off a series of adjustments across the economy, creating new rents and destroying existing rents.

The insight of Tullock's (1967) partial equilibrium analysis was that rent seekers will not behave passively in this way. In the context of our example, Tullock (1967) argued that producers in market B will use resources to capture rents in that market, and that consumers in market B will also use resources to oppose the introduction of the distortion. The devotion of these resources does not generate any additional production or income, and instead merely redistributes income, and so must be considered socially wasteful.

However, the analysis in section 2 makes it clear that when there are pre-existing distortions, there will be additional rent-seeking costs in other markets that need to be taken into account. For the same reasons as those identified by Tullock (1967), firms in related markets will be willing to use valuable resources to capture new rents, or to prevent existing rents from being destroyed. In a general equilibrium setup, Tullock's insight - combined with the standard general equilibrium welfare analysis - means that there are additional rent-seeking costs which must be taken into account - but which are ignored in partial equilibrium approaches to rent seeking.

\footnotetext{
${ }^{8}$ One of the key points made by Goulder and Williams (2003) is that partial equilibrium assessments of the welfare effect of changing the tax in market $i$ which ignore rectangle interaction terms will generally produce incorrect estimates of the excess burden of taxation. See Tresch (2003) for an exposition of the welfare effects of taxation when there are existing taxes in other markets.
} 
To see this, recall that in our example, the goods are assumed to be substitutes. Since there is an existing distortion in market $\mathrm{A}$, the imposition of the distortion in market $\mathrm{B}$ creates additional rents in both markets. That is, applying Tullock's (1967) insights, firms in market A will be willing to use valuable resources to capture those additional rents. In this particular case, the producers in market A will lobby in favour of the intervention in market B, precisely because they may gain additional rents from this intervention.

Thus, Tullock's (1967) partial equilibrium measure of the costs of rent seeking (i.e the rectangle in market B) will likely underestimate the total potential rent seeking costs. Producers in both markets will lobby in favour of the intervention and there are actually two potential sources of rent seeking costs, rather than one. Following Tullock's (1967) logic, producers in market B would be willing to spend up to $\delta_{B} x_{B}^{2}$ to encourage the establishment of the distortion in their market whilst, for the reasons just discussed, producers in market A would be willing to spend up to $\delta_{A}\left(x_{A}^{2}-x_{A}^{1}\right)$ to encourage the distortion in market $\mathrm{B}$, assuming that there is no overdissipation of rents..

The precise overall effect on welfare will depend on the fraction of rents that are dissipated in each market. Let $\theta_{\mathrm{A}}>0$ be the share of the rectangle in market A that is dissipated, and $\theta_{B}>0$ be the share of the rectangle in market A that is dissipated. ${ }^{9}$ When the goods are substitutes, the overall change in welfare as a result of the introduction of the new distortion in market $\mathrm{B}$ is

$$
\Delta W_{B}=\frac{1}{2} \delta_{B}\left(x_{B}^{2}-x_{B}^{1}\right)-\theta_{B} x_{B}^{2}+\left(1-\theta_{A}\right) \delta_{A}\left(x_{A}^{2}-x_{A}^{1}\right)
$$

We can compare this expression directly with equation (1) above. The first term in (2) is the Harberger triangle in market B and is the same as the first term in (1), whilst the second term is the Tullock rectangle in market $B$. If there is no rent dissipation in market B then this term vanishes. The third term is the increase in welfare in market $A$, less the rent seeking costs of

\footnotetext{
${ }^{9}$ The precise way in which these shares are determined would of course depend on the rent-seeking technology and the rules of the rent-seeking contest, and is not the main focus of our analysis.
} 
$\theta_{A} \delta_{A}\left(x_{A}^{2}-x_{A}^{1}\right)$ in that market. If there are no resources devoted to rent seeking in either market, then $\theta_{A}=\theta_{B}=0$ and we have the same expression for the change in welfare as we had in (1), and this can be positive if the term $\delta_{A}\left(x_{A}^{2}-x_{A}^{1}\right)$ is sufficiently large. In contrast, if there is perfect rent dissipation in each market (so that $\theta_{A}=\theta_{B}=1$ ), then it is not possible (2) to be positive.

The analysis is similar if A and B are complements, with appropriate minor modifications. When A and B are complements, the standard approach gives the same expression as (1) for the change in welfare. The only difference is that the introduction of the new distortion in B will cause the demand curve for good A to shift to the left, and so the term $\delta_{A}\left(x_{A}^{2}-x_{A}^{1}\right)$ in (1) is negative rather than positive as it was in the analysis of substitutes. Hence in the case of complements, it is not possible under the standard approach for the welfare change in (1) to be positive. Accounting for rent seeking costs simply reinforces this conclusion. Producers in market A will stand to lose $\delta_{A}\left(x_{A}^{2}-x_{A}^{1}\right)$. They will therefore have an incentive to lobby against the introduction of the new distortion in market $B$. The overall change in welfare as a result of the introduction of the new distortion in market $\mathrm{B}$ is

$$
\Delta W_{B}=\frac{1}{2} \delta_{B}\left(x_{B}^{2}-x_{B}^{1}\right)-\theta_{B} x_{B}^{2}+\left(1+\theta_{A}\right) \delta_{A}\left(x_{A}^{2}-x_{A}^{1}\right) .
$$

The only difference between (3) is the last term where, as in (2), the rent seeking costs again enter negatively.

\section{Implications}

There are a number of lessons to draw from this analysis. Firstly, irrespective of whether the goods are substitutes or complements, rent seeking activity will lead to additional social costs in related markets and, just as Tullock (1967) pointed out in the partial equilibrium case, those costs should be taken into account in computing overall welfare effects of interventions. Moreover, the implications are broader than our special example of positive distortions in markets with 
constant marginal cost curves would initially suggest. Consider, for example, the case in which the long run supply curve in an industry is upward sloping, so that the owners of the scarce factors responsible for the upward sloping supply curves enjoy economic rents. Then these factor owners would have an incentive to lobby for intervention in other markets, whether their own market is distorted or not. ${ }^{10}$ Again, the basic point of the preceding analysis still stands: by ignoring the rent-seeking incentives of producers in other markets, the standard Tullock rectangle will tend to underestimate the overall costs of rent-seeking.

Secondly, the results of our analysis contrast sharply with the general theory of second best [Lipsey and Lancaster (1956)] and the world of conventional welfare economics described in section 2. In that analysis, when the goods are substitutes, any interaction terms (ie changes in rectangles in other markets) would be counted as welfare gains, because they represent the net value of additional units of consumption for which marginal consumption benefits exceed marginal costs, which would not have otherwise occurred as a result of the intrpduction of a new distortion. In contrast, in the rent-seeking society only part of this area can be counted as a welfare gain when the goods are substitutes, and if there is full rent dissipation the term completely disappears. When the goods are complements, the interaction terms are losses under the standard approach, and accounting for rent-seeking costs exacerbates those losses.

Finally, our analysis lends further support to the analysis and conclusions of Sieper (1982), who notes that there is a potential for significant rent-seeking expenditures if producer interests are placed in direct opposition to each other. Sieper argues that the Australian political process has displayed a strong preference for the convention of limiting transfers to those that can be directly obtained in one's own market. ${ }^{11}$ Our analysis shows that since producers in other markets already have an indirect incentive to lobby for interventions elsewhere, allowing each industry to “own its own demand curve” will help limit direct competition, but would not eliminate wasteful

\footnotetext{
${ }^{10} \mathrm{I}$ am grateful to an anonymous referee for pointing this out.

${ }^{11}$ Sieper notes that throughout Australia's history such examples were common, including in the egg, dairy and wheat industries.
} 
rent seeking activity from other producers altogether, since the indirect lobbying incentives examined in this paper would remain.

It is clear from our analysis that the only case where these considerations are unimportant are when the goods are neither substitutes or complements. In that case, the welfare cost of rent seeking will be equal to its standard partial equilibrium trapezoid measure. Accounting for rectangle changes in other markets simply amounts to counting zeros, and we are back in Tullock's (1967) world. Thus, for the purposes of our analysis, substitutability and complementarity matter if and only if they are non-trivial in the usual economic sense. Thus, when trying to account for the possible incentives for establishing new distortions (and against removing existing distortions) in distorted economies, it would seem that the most analytically useful course of action would be to follow the advice of Harberger (1971) and only pay attention to those markets which (a) have economically significant existing distortions and (b) interact with the market under consideration in an economically significant way.

\section{Concluding Remarks}

This paper has shown that the presence of existence distortions may be an important determinant of the rents that are dissipated when a distortion is introduced in a particular market. As a result, the social costs of interventionist policies could in practice exceed the sum of the usual partial equilibrium measures originally developed by Harberger and Tullock. If a new intervention unravels or reinforces the effects of an existing policy somewhere else in the economy, this inevitably has consequences for rents and revenues in those markets. Existing rent-seekers are not innocent bystanders when it comes to the creation of new policies, and will not sit idly by and passively accept the consequences of new interventions. On the contrary, they will either lobby against them if rents are being destroyed, or lobby in favour of them if additional rents are being created. This point holds irrespective of whether the good in the sector that is being focused upon is a substitute or complement for other goods in the other sectors which are already subject to distortions. 
The size of the discrepancy between standard partial equilibrium measures and general equilibrium estimates of rent seeking costs and welfare effects will depend on the extent to which rents are dissipated in other sectors, the absolute size of the interdependence between the sectors, the size of the distortion in the sector being focused upon, and the size of pre-existing distortions in other markets. The additional interaction terms can be thought of as "HarbergerTullock rectangles”, because they combine Tullock's (1967) insights regarding the costs of rent seeking with Harberger's careful accounting of the welfare effects of distortions in a general equilibrium setting when there are existing distortions in other markets. Overall, the main conclusion of our analysis is analogous to that made by Goulder and Williams (2003) in the context of estimating the traditional costs of taxation: in computing the costs of rent seeking that occur as a result of the imposition of a particular distortion, it is not enough to simply examine rent-seeking behaviour and its costs in the market which is being subjected to the policy. Rentseeking behaviour and effects in related markets also need to be taken into account. 


\section{References}

Bhagwati, J. (1982) “Directly Unproductive, Profit-Seeking (DUP) Activities,” Journal of Political Economy, 90(5): 988-1002.

Bhagwati, J. and Srinivasan, T. (1980) "Revenue Seeking: A Generalization of the Theory of Tariffs,” Journal of Political Economy, 88(6): 1069-1087.

Congleton, R. Hillman, A., and Konrad, K. (2008) “Introduction” in Congleton, R. Hillman, A., and Konrad, K. (eds) 40 Years of Research on Rent Seeking, New York: Springer.

Goulder, L. and Williams, R. (2003) “The Substantial Bias from Ignoring General Equilibrium Effects in Estimating Excess Burden, and a Practical Solution,” Journal of Political Economy, 111(4): 898-927.

Grossman, G. and Helpman (2001) Special Interest Politics, Cambridge, MA: MIT Press.

Harberger, A. (1964) Taxation, Resource Allocation and Welfare, in The Role of Direct and Indirect Taxes in the Federal Reserve System, Princeton: Princeton University Press.

Harberger, A. (1971) “Three Basic Postulates for Applied Welfare Economics,” Journal of Economic Literature, 9(3): 785-797.

Hillman, A. (2009) Public Finance and Public Policy: Responsibilities and Limitations of Government, Second edition, New York: Cambridge University Press.

Hillman, A. (2013) "Rent Seeking”, Chapter 19 in Reksulak, M. et al The Elgar Companion to Public Choice, Second Edition, Cheltenham, UK: Edward Elgar.

Konrad, K. (2009) Strategy and Dynamics in Contests, New York: Oxford University Press.

Lipsey, R.G and Lancaster, K. (1956) “The General Theory of Second Best," Review of Economic Studies, 24(1): 11-32.

Mueller, D. (2003) Public Choice III, London: Cambridge University Press. 
Nitzan, S. (1994) “Modelling Rent Seeking Contests,” European Journal of Political Economy, 10: 41-60.

Sieper, E. (1982) Rationalising Rustic Regulation, Centre for Independent Studies, Sydney.

Stigler, G.J. (1971) "The Theory of Economic Regulation”, Bell Journal of Economics and Management Science, 2: 3--21.

Tresch, R. (2003) Public Finance: A Normative Theory, Second Edition, new York: Academic Press.

Tullock, G. (1967) “The Welfare Costs of Tariffs, Monopolies and Theft," Western Economic Journal, 5 (3): 224-232.

Varian, H. (1989) "Measuring the Deadweight Costs of DUP and Rent-Seeking Activities," Economics and Politics, 1: 81-95. 